\title{
Implementation of Quality Risk Management for Manufacturing of a Non-Sterile Pharmaceutical Product- Case study
}

\author{
Ahmed Assem* \\ MBA, Tabuk pharmaceuticals, Saudi Arabia \\ *Corresponding author: Ahmed Assem, MBA, Tabuk pharmaceuticals, Saudi Arabia

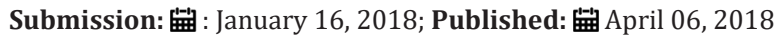

\begin{abstract}
This article will address a model for implementation of quality risk management for the manufacturing of a non-sterile product through a real case. The risk addressed in the article is the microbiological contamination and the procedure followed was Failure Mode Effect Analysis (FMEA) mainly. It can be used by pharmaceutical scientist to evaluate the possible causes of microbiological contamination of their products and will show how to evaluate the risks and describe a monitoring plan based on the associated risks
\end{abstract}

Keywords: Pharmaceutical microbiology; Quality risk management; Pharmaceutical manufacturing; Microbial contamination

\section{Introduction}

The holder of a manufacturing authorisation must manufacture medicinal products so as to ensure that they are fit for their intended use, comply with the requirements of the Marketing Authorisation and do not place patients at risk due to inadequate safety, quality or efficacy [1]. As Per ICH Q9, Quality Risk Management, "Risk management is the systematic application of quality management policies, procedures, and practices to the tasks of assessing, controlling, communicating and reviewing risk [2].

To protect patients in terms of quality, safety and efficacy of medicines, international medicines regulatory authorities (MRAs) are recommending pharmaceutical manufacturers to adopt a riskbased approach to the life-cycle of a pharmaceutical product [3]. The quality risk management system should ensure that [4]. The evaluation of the risk to quality is based on scientific knowledge, experience with the process and ultimately links to the protection of the patient; the level of effort, formality and documentation of the quality risk management process is commensurate with the level of risk.

\section{Procedure}

The following procedure will be used to perform the risk assessment (the risk addressed is the microbial contamination of a non-sterile product).

A. First step is to develop a process flow chart to fully describe the manufacturing process

B. Second step is to form a project team

C. A Cause \& Effect (Fishbone) diagram will be prepared by the team (using the process flow chart) to evaluate the possible causes of microbial contamination.
D. FMEA will be developed by the team (using the prepared Cause \& Effect diagram) to evaluate the risk associated with different factors (Raw materials, Packaging materials, Utilities, etc.)

E. Pareto diagram will be used to highlight the most critical factors that may lead to microbial contamination of the product (using the developed FMEA)

F. Finally, a monitoring plan will be developed to insure that all the identified high risk factors are monitored frequently to insure the risk (microbial contamination risk) is controlled

Implementation of a risk management process Identify process by plotting the process (Figure 1) [5]. Formation of the project team

The team should be composed of to reflect all function that could have a decision influence on quality or compliance

The team will include product-specific knowledge and expertise

The team will include:
A. The Quality Director
B. The Microbiology manager
C. The production manager
D. The engineering manager
E. The validation manager 


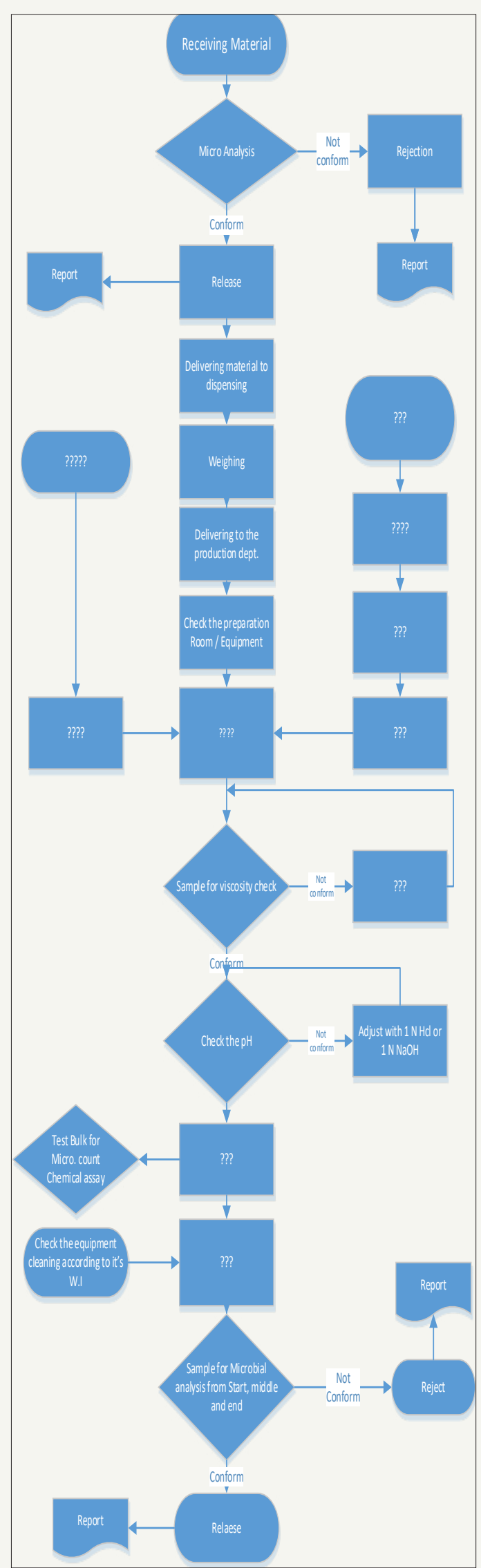

Figure 1 
The team will be responsible for:
A. Conduct a hazard analysis
B. Identify potential hazards
C. Identify hazards which should be controlled
D. Recommend controls and critical limit

E. Devise procedures for monitoring and verification

F. Recommend appropriate corrective action where deviations occur

\section{Methods of risk assessment}

One of the most common used methods is Fish -bone diagram which summaries all critical influencing variables on the product quality [6,7]; (Figure 2).

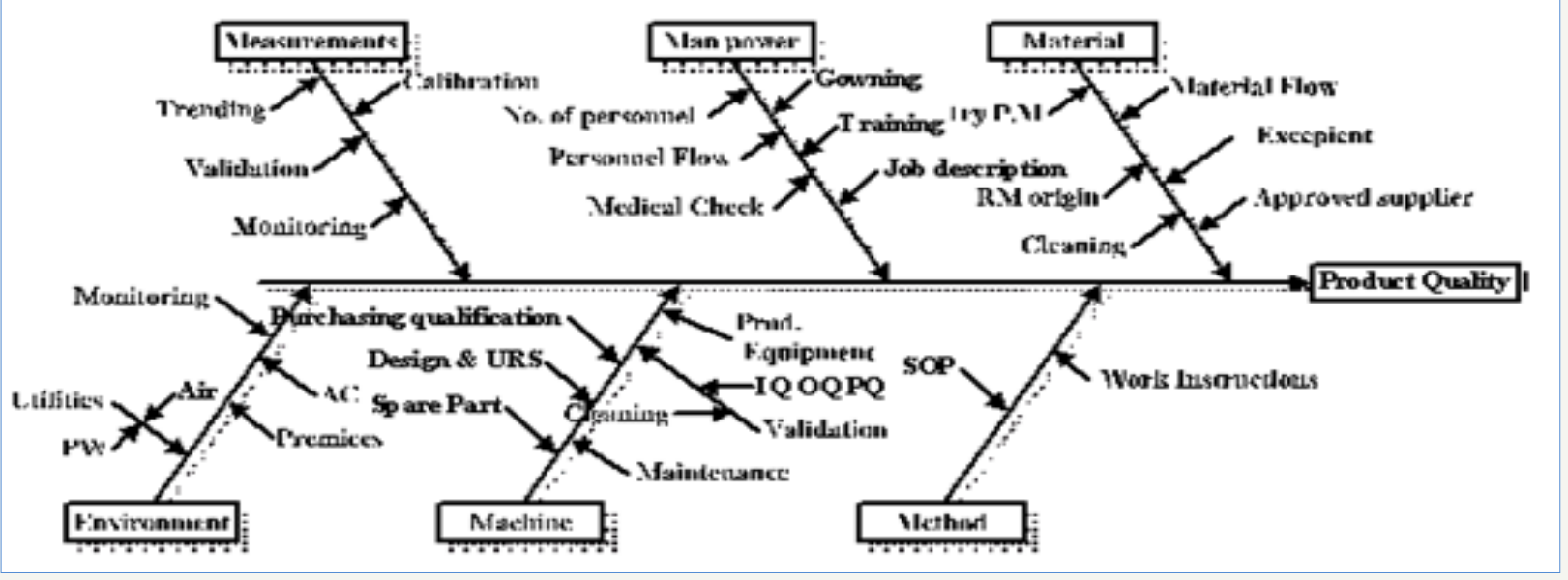

Figure 2: Cause \& Effect Diagram.

\section{Determining the risk ranking (using Pareto chart)}

Vilfredo Pareto was an Italian economist who lived from 1848to 1923. His study of the wealth distribution in the Italian economy yielded a key finding that $80 \%$ of the land was owned by $20 \%$ of the population. Since then, his discovery what we call the Pareto

\section{Risk assessment using FMEA $[8,9]$}

\section{Risk ranking policy}

(Tables 1-7)

Table 1: The Product.

\begin{tabular}{|c|c|c|c|}
\hline & Product Description & Raw Materials \& Qty. & The Intended Use \\
\hline The product name is XYZ & Code & Quantity \\
\hline 1. Pityriasis versicolor, & RM 1 & \\
\hline 2. sebororhoeic dermatitis & & \\
\hline 3. pityriasis capitis & RM 2 & $32 \mathrm{~kg}$ & \multirow{2}{*}{$\begin{array}{c}\text { Treatment and prophylaxis } \\
\text { of infectious diseases such } \\
\text { as }\end{array}$} \\
\hline $\begin{array}{c}\text { XYZ is a synthetic imidazole dioxolane derivative with } \\
\text { fungicidal properties. }\end{array}$ & RM 3 & $3.2 \mathrm{~kg}$ \\
\hline A plastic bottle containing 60 ml. & RM 4 & $1.5 \mathrm{~kg}$ \\
\hline $\begin{array}{c}\text { The product is intended for external use. } \\
\text { The following table showing the batch components of XYZ } \\
\text { shampoo. }\end{array}$ & RM 5 & RM: Raw material \\
\hline
\end{tabular}

principle has been found to hold true in many other situations. For problem solvers, the simple Pareto principle provides a powerful root cause analysis (RCA) tool to separate the vital few factors from the trivial many determining risk ranking for Raw materials \& Primary Packaging materials using the Pareto Chart. 
Table 2: The following table showing scoring policy.

\begin{tabular}{|c|c|c|c|}
\hline S.No & Probability & Severity & Detection \\
\hline 1 & Extremely Unlikely & None & Extremely Likely \\
\hline 2 & Low Likelihood & Minor & High Likelihood \\
\hline 3 & Medium Likelihood & Moderate & Medium Likelihood \\
\hline 4 & High Likelihood & High Severity & Low Likelihood \\
\hline 5 & Extremely Likely & Maximum Severity & Extremely Unlikely \\
\hline
\end{tabular}

Table 3: The following table showing Ranking policy.

\begin{tabular}{|c|c|}
\hline Risk Priority Number(RPN) & Class \\
\hline $1-12$ & Low \\
\hline $13-27$ & Moderate \\
\hline $28-125$ & High \\
\hline
\end{tabular}

Table 4: Risk Assessment for Raw Materials \& Packaging Material.

\begin{tabular}{|c|c|c|c|c|c|c|c|}
\hline & Hazard & Reason & Probability & Severity & Detection & RPN & Class \\
\hline \multirow{5}{*}{ Raw materials } & RM1 & $\begin{array}{c}\text { Potential } \\
\text { contamination } \\
\text { hazard }\end{array}$ & 4 & 4 & 3 & 48 & $\mathrm{H}$ \\
\hline & RM2 & $\begin{array}{c}\text { Potential } \\
\text { contamination } \\
\text { hazard }\end{array}$ & 4 & 4 & 3 & 48 & $\mathrm{H}$ \\
\hline & RM3 & $\begin{array}{c}\text { Potential } \\
\text { contamination } \\
\text { hazard }\end{array}$ & 2 & 4 & 3 & 24 & M \\
\hline & RM4 & $\begin{array}{c}\text { Potential } \\
\text { contamination } \\
\text { hazard }\end{array}$ & 2 & 4 & 3 & 24 & M \\
\hline & RM5 & $\begin{array}{c}\text { Potential } \\
\text { contamination } \\
\text { hazard }\end{array}$ & 1 & 4 & 3 & 12 & $\mathrm{~L}$ \\
\hline \multirow{3}{*}{$\begin{array}{l}\text { Packaging } \\
\text { Materials }\end{array}$} & Bottle & $\begin{array}{c}\text { Potential } \\
\text { contamination } \\
\text { hazard }\end{array}$ & 4 & 4 & 3 & 48 & $\mathrm{H}$ \\
\hline & Cap & $\begin{array}{c}\text { Potential } \\
\text { contamination } \\
\text { hazard }\end{array}$ & 2 & 4 & 3 & 24 & $\mathrm{M}$ \\
\hline & \multicolumn{7}{|c|}{ RPN: Risk Priority Number, H: High, M:medium, L: low } \\
\hline
\end{tabular}

Table 5: Risk Assessment of different processes.

\begin{tabular}{|c|c|c|c|c|c|c|}
\hline Hazard & Reason & Probability & Severity & Detection & RPN & Class \\
\hline $\begin{array}{c}\text { Receiving } \\
\text { material }\end{array}$ & $\begin{array}{c}\text { Contamination } \\
\text { through } \\
\text { damaged } \\
\text { containers }\end{array}$ & 1 & 4 & 2 & L \\
\hline $\begin{array}{c}\text { Sampling for } \\
\text { micro analysis }\end{array}$ & $\begin{array}{c}\text { Contamination } \\
\text { during sampling } \\
\text { procedure }\end{array}$ & 2 & 4 & 2 & 16 & M \\
\hline $\begin{array}{c}\text { Delivering RM to } \\
\text { dispensing }\end{array}$ & $\begin{array}{c}\text { Contamination } \\
\text { during delivering }\end{array}$ & 2 & 4 & 3 & 36 & $\mathrm{M}$ \\
\hline Dispensing & $\begin{array}{c}\text { Contamination } \\
\text { during the } \\
\text { dispensing }\end{array}$ & 3 & 4 & 2 & 16 & $\mathrm{M}$ \\
\hline $\begin{array}{c}\text { Delivering RM to } \\
\text { production }\end{array}$ & $\begin{array}{c}\text { Contamination } \\
\text { during transfer }\end{array}$ & 2 & 4 & 36 & $\mathrm{M}$ \\
\hline
\end{tabular}




\begin{tabular}{|c|c|c|c|c|c|c|}
\hline $\begin{array}{c}\text { Compounding } \\
\text { process }\end{array}$ & $\begin{array}{c}\text { Contamination } \\
\text { during } \\
\text { compounding }\end{array}$ & 3 & 4 & 4 & 48 & $\mathrm{H}$ \\
\hline Filling process & $\begin{array}{c}\text { Contamination } \\
\text { during the filling }\end{array}$ & 4 & 4 & 5 & 80 & H \\
\hline \multicolumn{7}{|c|}{ RPN: Risk Priority Number, H: High, M:medium, L: low } \\
\hline
\end{tabular}

Table 6: Risk Assessment of different Utilities, Equipments and machines.

\begin{tabular}{|c|c|c|c|}
\hline Hazard & Reason & Probability & Severity \\
\hline Purified Water & $\begin{array}{c}\text { Contamination through low } \\
\text { micro. quality }\end{array}$ & 4 \\
\hline Compressed Air & $\begin{array}{c}\text { Contamination through low } \\
\text { micro. quality }\end{array}$ & 2 & 4 \\
\hline Different production machines. & $\begin{array}{c}\text { Contamination by unclean } \\
\text { machine }\end{array}$ & 2 & 4 \\
\hline The filling machine & $\begin{array}{c}\text { Contamination during the } \\
\text { filling }\end{array}$ & 2 & 4 \\
\hline Connection of tank \& machine & $\begin{array}{c}\text { Contamination through } \\
\text { connection }\end{array}$ & 2 & 4 \\
\hline
\end{tabular}

Table 7: Risk Assessment of different premises.

\begin{tabular}{|c|c|c|c|c|c|c|}
\hline Hazard & Reason & Probability & Severity & Detection & RPN & Class \\
\hline \multicolumn{7}{|c|}{ Dispensing Area } \\
\hline Air & Poor air quality & 3 & 4 & 5 & 36 & $\mathrm{H}$ \\
\hline \multirow[t]{2}{*}{ Personnel } & Lack of training, & 2 & 4 & 3 & 24 & $\mathrm{~L}$ \\
\hline & $\begin{array}{l}\text { Uncontrolled } \\
\text { Gowning. }\end{array}$ & 1 & 4 & 2 & 20 & $\mathrm{~L}$ \\
\hline Cleaning & $\begin{array}{l}\text { Inefficient } \\
\text { cleaning } \\
\text { program }\end{array}$ & 1 & 4 & 3 & 12 & M \\
\hline \multicolumn{7}{|c|}{ Production Rooms (Compounding \& Filling) } \\
\hline Air & Poor air quality & 3 & 4 & 3 & 36 & $\mathrm{H}$ \\
\hline \multirow[t]{2}{*}{ Personnel } & Lack of training, & 2 & 4 & 3 & 24 & M \\
\hline & $\begin{array}{l}\text { Uncontrolled } \\
\text { Gowning. }\end{array}$ & 1 & 4 & 5 & 20 & $\mathrm{~L}$ \\
\hline Cleaning & $\begin{array}{l}\text { Inefficient } \\
\text { cleaning } \\
\text { program }\end{array}$ & 1 & 4 & 3 & 12 & M \\
\hline
\end{tabular}

\section{Determining the risk ranking (using Pareto chart)}

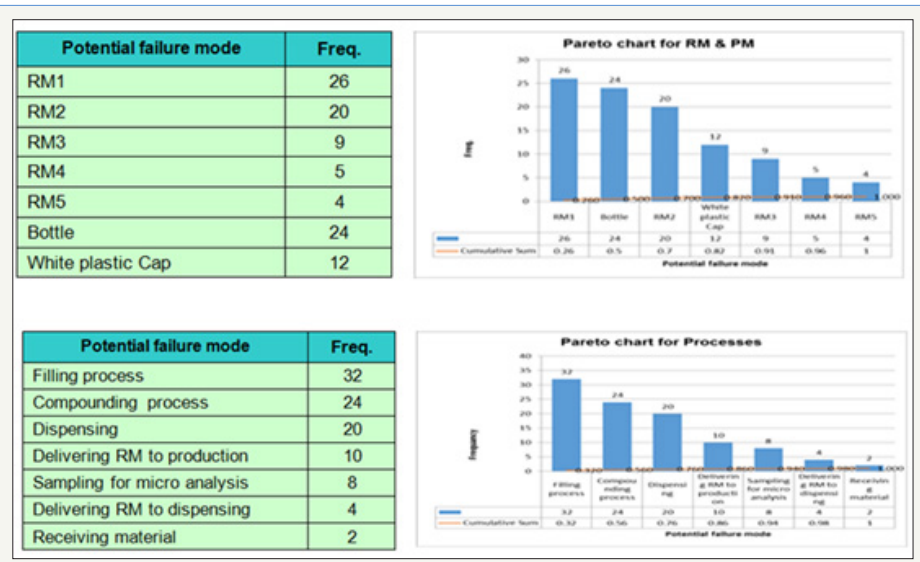

Figure 3:Determining Risk Ranking for different Processes using the Pareto Chart. 
Vilfredo Pareto was an Italian economist who lived from 1848 to 1923 . His study of the wealth distribution in the Italian economy yielded a key finding that $80 \%$ of the land was owned by $20 \%$ of the population. Since then, his discovery what we call the Pareto principle has been found to hold true in many other situations. For problem solvers, the simple Pareto principle provides a powerful root cause analysis (RCA) tool to separate the vital few factors from the trivial many [10]. Determining Risk Ranking for Raw materials \& Primary Packaging materials using the Pareto Chart [11,12]; (Figure 3).

\section{Conclusion}

Using the QRM the following monitoring plan was developed which can be considered an effective monitoring plan. The developed plan is highly effective as it will monitor the most critical factors that may cause microbial contamination in a non-sterile product and it found to be a cost effective plan as it will eliminate monitoring the factors that will not affect the product quality (Table 8).

\section{Table 8:}

\begin{tabular}{|c|c|}
\hline Risk Factor & Monitoring Plan \\
\hline RM 1 & Microbial testing for each lot received \\
\hline RM 2 & Microbial testing for each lot received \\
\hline Bottles & Microbial testing for each lot received \\
\hline Dispensing & Environmental monitoring of the dispensing area on weekly basis \\
\hline Compounding & Environmental monitoring of the compounding area on weekly basis \\
\hline Filling process & Environmental monitoring of the filling area on weekly basis \\
\hline Purified water & $\begin{array}{l}\text { Microbiological testing of purified water used in the preparation of the } \\
\text { product or the cleaning of surface come in direct contact with the product } \\
\text { on weekly basis }\end{array}$ \\
\hline Different production machines & $\begin{array}{l}\text { All machines/ equipments that come in direct contact with the product to } \\
\text { be included in the cleaning validation program }\end{array}$ \\
\hline Air & $\begin{array}{l}\text { Air quality in compounding area, filling area \& dispensing area should be } \\
\text { tested for microbiological quality on weekly basis }\end{array}$ \\
\hline
\end{tabular}

\section{References}

1. Eudra Lex (2010) EC guidelines to Good Manufacturing Practice (GMP) for human and veterinary medicinal products chapter 1 pharmaceutical quality system; European Commission.

2. Quality Guideline (2005) Q9: quality risk management; international conference on harmonization.

3. Good manufacturing practices (2014) WHO guidelines on quality risk management. In: WHO expert committee on specifications for pharmaceutical preparations. Forty-seventh report. World Health Organization, Geneva, Switzerland.

4. L Viornery (2010) Quality Risk Management, Implementation of ICH Q9 in the pharmaceutical field an example of methodology from PIC/S, $\mathrm{PIC} / \mathrm{S}$.
5. ASQ Flow Chart Template.

6. ASQ Fishbone (Ishikawa) Diagram.

7. ASQ Fishbone diagram template.

8. ASQ Failure Mode Effects Analysis (FMEA).

9. (2003) Guidelines for Failure Modes and Effects Analysis (FMEA) for Medical Devices, Dyadem Press.

10. Bhalla, Aditya (2009) Don't misuse the pareto principle. ASQ six sigma forum magazine 3: 15-18.

11. ASQ Pareto Chart.

12. ASQ Pareto Chart Template.
Creative Commons Attribution 4.0 International License

For possible submissions Click Here

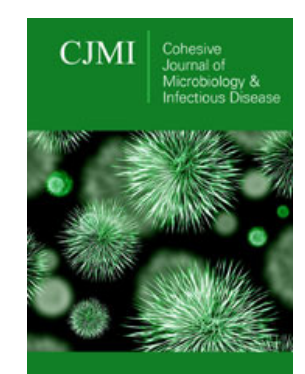

Approaches in Poultry, Dairy \& Veterinary Sciences

\section{Benefits of Publishing with us}

- High-level peer review and editorial services

- Freely accessible online immediately upon publication

- Authors retain the copyright to their work

- Licensing it under a Creative Commons license

- Visibility through different online platforms 